\title{
$N$-Methyl-D-Aspartate Receptors in the Basolateral Amygdala Are Required for Both Acquisition and Expression of Conditional Fear in Rats
}

\author{
Stephen Maren, Gal Aharonov, Deborah L. Stote, and Michael S. Fanselow \\ University of California, Los Angeles
}

\begin{abstract}
Three experiments examined the effects of intra-amygdaloid infusions of an $N$-methyl-Daspartate (NMDA) receptor antagonist, D,L-2-amino-5-phosphonovalerate (APV), on contextual fear conditioning in rats. In Experiment 1, APV infusion into the basolateral amygdala (BLA), before training, disrupted the acquisition of contextual fear. In Experiment 2, APV produced a disruption of both the acquisition and expression of contextual fear. This blockade of contextual fear was not state dependent, not due to a shift in footshock sensitivity, and not the result of increased motor activity in APV-treated rats. In Experiment 3, fear conditioning was not affected by a posttraining APV infusion into the BLA. These results indicate that NMDA receptors in the BLA are necessary for both the acquisition and expression of Pavlovian fear conditioning to contextual cues in rats.
\end{abstract}

The association of stimuli and their aversive consequences is a ubiquitous form of learning with obvious adaptive value. One model system for studying the neural substrates underlying aversive learning is Pavlovian fear conditioning in rats. In Pavlovian fear conditioning, an initially neutral stimulus (conditional stimulus, or CS), such as a tone or context, comes to elicit a conditional fear response, such as somatomotor immobility (i.e., freezing), after being paired with an aversive unconditional stimulus (US), such as an electric footshock. In recent years, the understanding of the neural substrates of aversive learning has grown abundantly, and considerable data indicate that the nuclei of the amygdala are essential (for reviews, see Davis, 1992; LeDoux, 1995; Maren \& Fanselow, 1996). For instance, destruction of neurons intrinsic to the basolateral amygdala (BLA) produces severe deficits in both the acquisition and the expression of conditional fear (Campeau \& Davis, 1995; Helmstetter, 1992; Maren, Aharonov, \& Fanselow, 1996; Sananes \& Davis, 1992). Indeed, conditional fear can be abolished by selective BLA lesions up to 1 month after training (Maren et al., 1996). In addition, associative neuronal firing emerges in the BLA during aversive conditioning (Maren, Poremba, \& Gabriel, 1991; Quirk, Repa, \& LeDoux, 1995), and pharmacological inactivation of the BLA disrupts both the learning and performance of conditional fear (Helmstetter \& Bellgowan, 1994).

Stephen Maren, Gal Aharonov, Deborah L. Stote, and Michael S. Fanselow, Department of Psychology, University of California, Los Angeles.

This work was supported by National Institute of Mental Health Grant MH39786 and National Institute of Mental Health National Research Service Award MH11061.

Correspondence concerning this article should be addressed to Stephen Maren, who is now at Department of Psychology, University of Michigan, 525 E. University Avenue, Ann Arbor, Michigan 48109-1109. Electronic mail may be sent via Internet to maren@ umich.edu.
Collectively, these data suggest that the BLA may be a critical locus for CS-US association formation during fear conditioning.

Although a number of studies point to the BLA as the locus for associative changes during fear conditioning, relatively little is known concerning the cellular mechanisms of CS-US association. One possibility is that the acquisition of fear conditioning requires an $N$-methyl-Daspartate (NMDA) receptor-dependent form of synaptic plasticity, such as long-term potentiation (LTP; Bliss \& Collingridge, 1993), which has been suggested to be involved in aversive learning and memory (e.g., Davis, Rainnie, \& Cassell, 1994; Fanselow, 1993; LeDoux, 1995). By this view, conditional fear may be the product of associative LTP in CS projections to the BLA, which could be induced by coincidental activity in the initially weak CS and strong US pathways (e.g., Kelso, Ganong, \& Brown, 1986). In keeping with this, several reports have described LTP in the BLA both in vitro (Chapman, Kairiss, Keenan, \& Brown, 1990) and in vivo (Clugnet \& LeDoux, 1990; Maren \& Fanselow, 1995). Moreover, it has been shown that blockade of NMDA receptors by infusion of D,L-2-amino-5phosphonovalerate (APV; a selective NMDA receptor antagonist) into the BLA disrupts the acquisition, but not expression, of conditional fear (Campeau, Miserendino, \& Davis, 1992; Miserendino, Sananes, Melia, \& Davis, 1990). Because NMDA receptors typically have a minimal contribution to normal synaptic transmission (Collingridge, Kehl, \& McLennan, 1983; Maren, Baudry, \& Thompson, 1992; Sah, Hestrin, \& Nicoll, 1989), the effects of APV on fear conditioning appear to be mediated through a blockade of LTP induction. In support of this, we have recently shown that excitatory, glutamatergic projections from the hippocampal formation (HF) to the BLA (a putative neural pathway for contextual CSs) exhibit LTP and that the LTP induced in the BLA by HF stimulation is blocked by APV (Maren \& Fanselow, 1995). 
The disruption of fear conditioning by infusion of NMDA receptor antagonists into the BLA is consistent with a role for BLA LTP in this form of learning. However, there are alternative interpretations for these results. One possibility is that the dissimilar drug states present during training and testing in the aforementioned studies produced a generalization decrement that degraded performance. It is possible, for instance, that the performance of rats trained with APV would be normal if they were also tested with APV. A second possibility is that intra-amygdaloid APV affects fear conditioning by disrupting a posttraining memory consolidation process that requires NMDA receptor activation (e.g., Liang, Hon, \& Davis, 1994), rather than disrupting CS-US association per se. In the following experiments, we examined these possibilities in a contextual-fear-conditioning task in rats. We concluded that NMDA receptor activation in the BLA is required, in a state-independent fashion, for both the acquisition and expression of conditional fear and that immediate posttraining infusion of APV is not sufficient to disrupt the acquisition of conditional fear.

\section{Experiment 1}

It has been reported that infusion of APV into the BLA disrupts the acquisition of contextual fear conditioning (Fanselow \& Kim, 1994). The first experiment was designed to replicate this effect under slightly different conditions than those used in the initial report. Two groups of rats were trained after the infusion of either APV or artificial cerebrospinal fluid (CSF) into the BLA, and a third group, which served as a control for the effects of intra-amygdaloid infusion, received no infusion before training. Conditional freezing was scored during both training and an infusionfree test the day after conditioning.

\section{Method}

Subjects. The subjects were 32 adult male Long-Evans rats (334-492 g), born and reared in the Department of Psychology vivarium at the University of California, Los Angeles. After weaning, the rats were group housed in same-sex cohorts. At the beginning of the experiment, the rats were individually housed in conventional stainless steel hanging cages on a 14:10-hr light-dark cycle (lights on at 7 a.m.), with free access to food and tap water. After individual housing, the rats were handled daily (10-20 s per rat) for 5 days, to acclimate them to the experimenter. All behavioral testing was performed during the light phase of the cycle.

Surgery. One week before behavioral testing, the rats were implanted with guide cannulas, aimed at the BLA. We anesthetized the rats with an injection of sodium pentobarbital $(65 \mathrm{mg} / \mathrm{kg}$ ip) and mounted them in a stereotaxic apparatus (Kopf Instruments, Tujunga, CA). The scalp was incised and retracted, and head position was adjusted to place bregma and lambda in the same horizontal plane. Small burr holes ( $1 \mathrm{~mm}$ diameter) were drilled in the skull for the bilateral placement of guide cannulas (26 gauge; Plastics Products, Roanoke, VA), dorsal to the BLA (2.3 mm posterior to bregma, $5.0 \mathrm{~mm}$ lateral to bregma, and $6.3 \mathrm{~mm}$ ventral to dura), and three small jeweler's screws. We used dental acrylic to affix the cannulas to the skull and to fill the scalp incision. After surgery, 33-gauge dummy cannulas (Plastics Products, Roanoke, VA), which extended $1 \mathrm{~mm}$ beyond the guide cannulas, were inserted into the guides, and the rats were allowed to recover on a heating pad before returning to their home cage. The dummies were replaced every other day with clean dummies during the 7-day recovery period. Five subjects were eliminated from the experiment because either their guide cannulas became clogged or they dislodged their acrylic cap.

Behavioral apparatus. Four identical observation chambers $(28 \times 21 \times 22 \mathrm{~cm}$; Lafayette Instruments, Lafayette, IN) were used for both conditioning and contextual fear testing. The chambers were situated in chests located in a dimly lit and isolated room. Ambient light in the room was provided by a single lamp, equipped with a $15-\mathrm{W}$ red light bulb. A videocamera placed in front of the observation chambers allowed each subjects' behavior to be observed and recorded by an experimenter in an adjacent room. The chambers were constructed from aluminum (sidewalls) and Plexiglas (rear wall, ceiling, and hinged front door). The floor of each chamber consisted of 17 vertically staggered stainless steel rods (4-mm diameter), spaced $1.5 \mathrm{~cm}$ apart (center to center). The rods were wired to a shock generator and scrambler (Lafayette Instruments, Lafayette, IN), for the delivery of footshock USs. The outside of the rear wall of each chamber was covered with white construction paper. In addition, a white, opaque Plexiglas tent was inserted into each chamber, so that the apex of the tent contacted the roof of the chamber and the open base of the tent fit into the bottom corners of the chamber. Background noise $(70 \mathrm{~dB} ; \mathrm{A})$ was supplied by a white-noise generator and adjacent shock scramblers. The chambers were cleaned with a $1 \% \mathrm{v} / \mathrm{v}$ acetic acid solution, and stainless steel pans containing a thin film of the same solution were placed underneath the grid floors before rats were placed inside.

Procedure. One week after surgery, the rats were transported to the laboratory in squads of 2 rats. On arrival, the dummies were removed from the rats and replaced by 33 -gauge injection cannulas (Plastics Products, Roanoke, VA), which extended $1 \mathrm{~mm}$ beyond the guide cannulas into the BLA. The rats were placed in holding cages similar to their home cages and were administered an infusion of artificial CSF ( $120 \mathrm{mM} \mathrm{NaCl}, 3 \mathrm{mM} \mathrm{KCl}, 2 \mathrm{mM} \mathrm{MgCl}$, $2 \mathrm{mM} \mathrm{CaCl}_{2}, 1.2 \mathrm{mM} \mathrm{NaH}_{2} \mathrm{PO}_{4}, 23 \mathrm{mM} \mathrm{NaHCO}_{3} ; \mathrm{pH} 7.4 ; n=9$ ); APV $(10 \mu \mathrm{g} / \mu \mathrm{l}, 51 \mathrm{mM}$; Sigma Chemical, St. Louis, MO; $n=9)$ in $\mathrm{CSF}$; or no infusion (none; $n=9$ ). The infusions were made with a $10-\mu$ Hamilton syringe, which was mounted in an infusion pump (Harvard Apparatus, South Natick, MA) and connected to the injection cannula with polyethylene tubing (PE-20). A total volume of $0.5 \mu \mathrm{l}$ was infused into the BLA over a 5 -min period (an infusion rate of $0.1 \mu \mathrm{l} / \mathrm{min})$; this yielded an infusion of $5 \mu \mathrm{g}(25.4 \mathrm{nmol})$ of APV into each amygdala. The slow infusion rate was chosen because pilot experiments revealed that a faster infusion rate $(0.25$ $\mu \mathrm{l} / \mathrm{min}$ ) disrupted conditioning in CSF controls. During the infusions, an experimenter was assigned to each rat and was responsible for preventing the rat from becoming entangled in the polyethylene tubing. The experimenter also distracted the rats with a pencil to discourage grooming during the infusion, because grooming often dislodged the injection cannulas. One minute was allowed after infusion for diffusion of the drug, after which the dummies were replaced and the rats were placed in the conditioning chambers.

Three minutes after being placed in the chambers, the rats received three unsignaled footshocks $(1 \mathrm{~s}, 1.0 \mathrm{~mA} ; 20$-s intershock interval). The rats were returned to their home cages and transported back to the vivarium $64 \mathrm{~s}$ after the final shock. Fear conditioning on the training day was assessed by measuring freezing during the 64-s period after the last shock trial (i.e., immediate postshock freezing). Briefly, an observer who was unaware of the experimental conditions scored each rat for freezing (behavioral immobility except for movement necessitated by respiration) every $8 \mathrm{~s}$, for a total of eight observations per animal. Fear conditioning to the context was assessed by returning the rats 
to the conditioning chambers, $24 \mathrm{hr}$ after training, and scoring freezing during an 8-min extinction test, yielding a total of 64 abservations per rat.

Histology. Histological verification of cannula location was performed after behavioral testing. Rats were perfused across the heart with $0.9 \%$ saline followed by $10 \%$ formalin solution. After extraction from the skull, the brains were postfixed in $10 \%$ formalin solution for 2 days and $10 \%$ formalin $30 \%$ sucrose solution until sectioning. Coronal sections $(50 \mu \mathrm{m}$ thick, taken every $200 \mu \mathrm{m})$ were cut on a cryostat $\left(-16^{\circ} \mathrm{C}\right)$ and wet mounted on glass microscope slides with $70 \%$ ethanol. After drying, the sections were stained with $0.25 \%$ thionin, to visualize neuronal cell bodies. Examination of the tissue sections revealed that all but 1 rat, which was in the APV group, had bilaterally symmetric placements in the BLA (see Figure 1 for a representative placement). The rat with the inaccurate cannula placement was excluded from the statistical analysis.

Data analysis. For each test period, the freezing data were transformed to a percentage of total observations, a probability estimate that is amenable to analysis with parametric statistics. These probability estimates of freezing were analyzed through analysis of variance (ANOVA). Immediate postshock freezing was submitted to a one-way ANOVA, with a between-subjects variable of group (three levels: APV vs. CSF vs. none), and the delayed freezing data were submitted to a two-way ANOVA, with a between-subjects variable of group and a within-subject variable of test minute block (four levels; four 2-min blocks). Planned comparisons in the form of Fisher's least significant difference (LSD) tests were performed, following a significant omnibus $F$ ratio. All data are represented as means, plus or minus the standard errors of measurement.

\section{Results and Discussion}

As shown in Figure 2, APV infusion into the BLA disrupted both immediate postshock freezing (see Figure $2 \mathrm{~A})$ on the conditioning day and delayed freezing on the 8-min context test (see Figure 2B). In addition, rats receiving CSF infusion did not differ from no-infusion controls.
These impressions were confirmed by significant main effects of group in the analysis of immediate postshock freezing, $F(2,23)=7.8, p<.005$, and delayed freezing, $F(2,23)=18.3, p<.0001$. Moreover, planned comparisons for both measures of conditional fear confirmed that the APV group reliably differed from both the CSF and noinfusion groups, which did not differ from one another. Thus, NMDA receptors are required for the acquisition of conditional fear that is expressed both on the conditioning day and during the delayed test.

\section{Experiment 2}

Experiment 1 revealed that intra-amygdaloid APV infusion disrupts Pavlovian fear conditioning to contextual CSs. One factor that may account for the deficits in conditional fear in APV-treated rats (at least the deficits that are apparent in the delayed-context test) is the change in behavioral state from training to testing. In other words, the dissimilar drug states of the APV rats during training and testing may have produced a generalization decrement during the test, which could account for the low level of freezing in APV-treated rats. To address this concern, we manipulated drug state during training and testing, in a $2 \times 2$ factorial design. Thus, rats received either APV or CSF immediately before training, testing, or both. Furthermore, to extend the results of Experiment 1 to a more robust fear-conditioning procedure, the footshock duration and intershock interval were increased in Experiment 2, to generate greater levels of conditional freezing in the control subjects (Fanselow \& Tighe, 1988).

\section{Method}

Subjects and surgery. The subjects were 20 adult male LongEvans rats $(407-540 \mathrm{~g})$, born and reared in the Department of

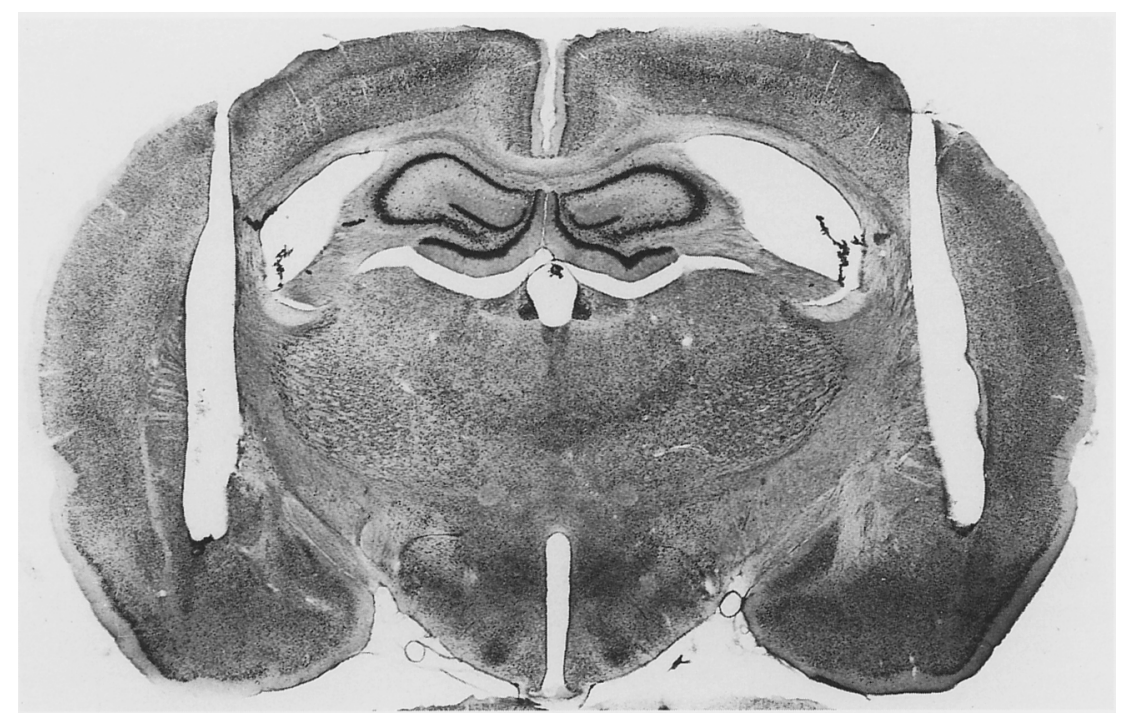

Figure 1. Photomicrograph showing a coronal section of the brain from a rat with representative cannula placements. Note that the placements of the guide cannulas (indicated by the cannula tracks) are just dorsal to the basolateral amygdala. 
A

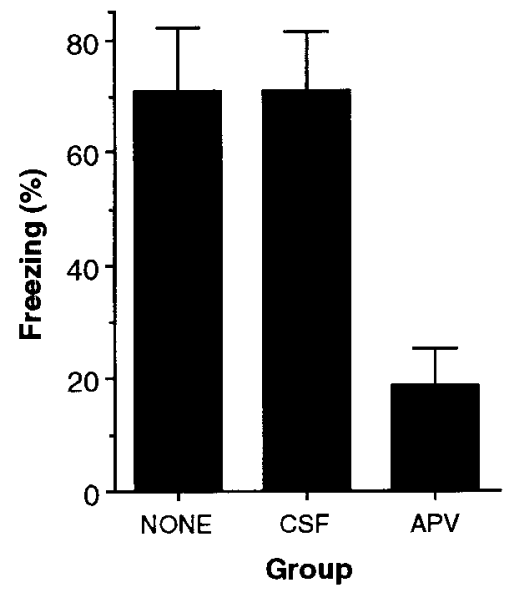

B

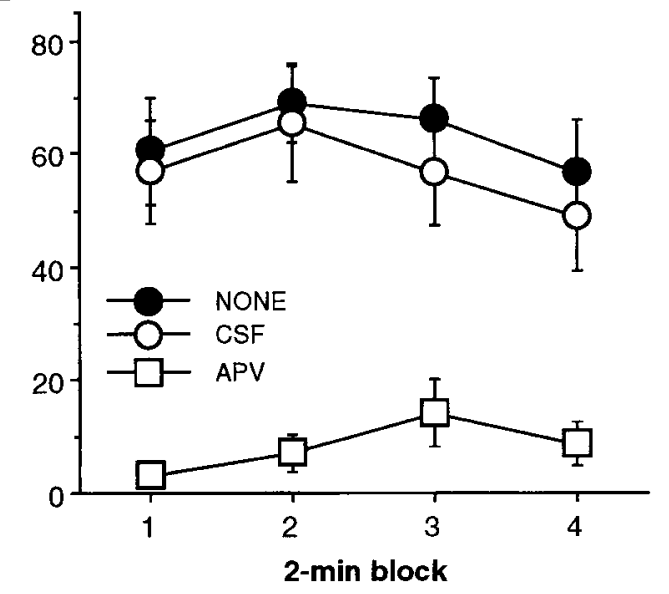

Figure 2. A: Mean percentage of freezing ( $\pm S E M$ ) during training in rats receiving no infusion (NONE), intra-amygdaloid cerebrospinal fluid infusion (CSF), or intra-amygdaloid D,L-2-amino-5phosphonovalerate (APV) infusion. Freezing was scored during the 64-s period after the last shock trial. Rats receiving intra-amygdaloid APV exhibited reliably lower levels of freezing than rats receiving either artificial CSF infusion or no infusion. B: Mean percentage of freezing $( \pm S E M)$ during the 8-min context-extinction test in the groups described in A. Again, rats treated with intra-amygdaloid APV exhibited reliably lower levels of freezing than those receiving either CSF or no infusion.

Psychology vivarium at the University of California, Los Angeles. All housing, handling, and surgical procedures were identical to those described in Experiment 1.

Behavioral apparatus and procedure. Four observational chambers similar to those used in Experiment 1 were used for both conditioning and contextual fear testing. The chambers were situated in a chest, located in a brightly lit and isolated room. The floor of each chamber consisted of 18 unstaggered stainless steel rods (4-mm diameter), spaced $1.5 \mathrm{~cm}$ apart (center to center). The rods were wired to a shock generator and scrambler (Lafayette Instruments, Lafayette, IN), for the delivery of footshock USs. The chambers were cleaned with a $5 \% \mathrm{v} / \mathrm{v}$ ammonium hydroxide solution, and stainless steel pans, containing a thin film of the same solution, were placed underneath the grid floors before rats were placed inside. Background noise (70 $\mathrm{dB}$; A) was supplied by ventilation fans in each chest and adjacent shock scramblers.

One week after surgery, we assigned the rats randomly to each cell of the $2 \times 2$ design, which had factors of training (two levels: APV vs. CSF) and testing (two levels: APV vs. CSF). This yielded four groups ( $n=5$ per group): CSF-CSF, APV-CSF, CSF-APV, and APV-APV. On the conditioning day, the rats were tested in squads of 4 , and all transport and infusion procedures were the same as those described in Experiment 1. After infusion, the rats were placed in the conditioning chambers and, after $3 \mathrm{~min}$, were administered three unsignaled footshocks $(2 \mathrm{~s}, 1.0 \mathrm{~mA} ; 64-\mathrm{s}$ intershock interval). The rats were returned to their home cages and transported back to the vivarium $64 \mathrm{~s}$ after the final shock. We assessed fear conditioning on the training day by measuring freezing during the 64-s period before the first (baseline) trial and after each of the three shock trials. During the 3-min preshock period, we assessed the number of ambulatory crossovers (horizontal translocations of the rat from one side of the conditioning chamber to the other), to examine whether intra-amygdaloid APV affects locomotor activity. The rats were again transported to the lab and infused, $24 \mathrm{hr}$ after training. After the infusion, fear conditioning to the training context was assessed, by returning the rats to the conditioning chambers and scoring freezing during a 6-min extinction test. The next day, the rats were given another extinction test; however, the infusion procedure was omitted.

Activity burst analysis. To assess the effects of intraamygdaloid APV on the perception of the footshock US, footshockelicited activity bursts were quantified (e.g., Fanselow, DeCola, \& Young, 1993). Activity-burst data were collected for rats in the CSF-CSF and APV-CSF groups (renamed $1.0 \mathrm{~mA}-\mathrm{CSF}$ and 1.0 $m A-A P V$, respectively, for this analysis), as well as for rats $(n=6)$ that received low-intensity footshocks $(2 \mathrm{~s}, 0.5 \mathrm{~mA})$ in another experiment. Data from the low-intensity rats were used to assess the sensitivity of the activity-burst measure to different footshock intensities. To quantify activity bursts, videotaped data from the training sessions were digitized on a Power Macintosh $8100 / 80 \mathrm{AV}$ computer, by means of NIH Image software. ' For each rat, two 2-s epochs ( 20 frames at 10 frames/s; 8 bit or 256 grey levels) were captured from the videotapes. The epochs occurred $4 \mathrm{~s}$ before the first footshock during training (preshock) or during the first 2-s footshock (shock) of the training session. To generate a measure of each rat's activity during these epochs, serial subtractions were performed on the digitized frames (i.e., Frame 2 - Frame 1, Frame 3 - Frame 2 ... Frame 20 - Frame 19), to yield 19 subtracted images for each epoch. The mean grey level for each subtracted image was measured (range $=-256$ to 256 ; a value of 0 would indicate no color change between the two images), and the absolute values of the grey levels for the 19 subtracted images were averaged, to yield a mean grey change ( $\Delta$ grey) for each 2-s epoch. As is shown below, $\Delta$ grey is a sensitive measure of footshockelicited activity bursts.

${ }^{1}$ Developed at the U.S. National Institutes of Health and available from the Internet by anonymous FTP from zippy.nimh. nih.gov or on floppy disk from the National Technical Information Service, Order Processing Division 5285 Port Royal Road, Springfield, Virginia 22161 (Part No. PB95-500195GEI). 
Histology. Histological verification of cannula location was performed according to the procedures described in Experiment 1. Examination of the tissue sections revealed that all of the rats had bilaterally symmetric placements in the BLA (see Figure 1 for a representative placement).

Data analysis. Immediate postshock freezing data were submitted to a two-way ANOVA, with a between-subjects variable of group (two levels: APV vs. CSF) and a within-subject variable of test period (four levels: baseline vs. three postshock periods). Preshock crossover data were submitted to a one-way ANOVA, with a between-subjects variable of group (two levels: APV vs. $\mathrm{CSF}$ ). For these analyses, the two groups receiving APV during training were collapsed; the same procedure was applied to the CSF groups. Delayed-freezing data, collapsed across the 6-min test, were submitted to a two-way ANOVA, with between-subjects variables of training (two levels: APV vs. CSF) and testing (two levels: APV vs. CSF). Because the second extinction test was conducted without drug infusion, the freezing data were submitted to a one-way ANOVA, with a between-subjects variable of group (four levels). Footshock-elicited activity data were submitted to a two-way ANOVA, with a between-subjects variable of group (three levels: $1.0 \mathrm{~mA}-\mathrm{APV}$ vs. $1.0 \mathrm{~mA}-\mathrm{CSF}$ vs. $0.5 \mathrm{~mA}$ ) and a within-subject variable of epoch (two levels: preshock and shock). Planned comparisons, in the form of Fisher's LSD tests, were performed, following a significant omnibus $F$ ratio. All data are represented as means, plus or minus the standard errors of measurement.

\section{Results and Discussion}

Ambulatory crossovers. Intra-amygdaloid APV infusion did not significantly alter the number of preshock cross- overs (for CSF, $M=11.3, S E M=0.9$; for APV, $M=9.2$, $S E M=0.5) ; F(1,18)=4.2, p=.054$. Thus, it did not appear that intra-amygadaloid APV altered motoric activity in the conditioning chambers during the 3-min preshock period.

Immediate postshock freezing. As shown in Figure 3A, intra-amygdaloid APV infusion before training severely blunted the acquisition of immediate postshock freezing, compared with CSF controls. This was confirmed with an ANOVA, by a reliable main effect of group, $F(1,18)=16.7$, $p<.001$, and a reliable Group $\times$ Test Period interaction, $F(3,54)=11.2, p<.0001$. Although APV-treated rats were attenuated in their acquisition of conditional fear, compared with CSF controls, they nonetheless increased their level of postshock freezing across the training trials. Planned comparisons indicated that postshock freezing after the second and third trials was reliably greater than the preshock freezing baseline in APV-treated rats.

Delayed freezing. Conditional freezing on the first context-extinction test is shown in Figure 3B. It is apparent that APV disrupted both the learning and performance of contextual freezing. This was indicated in the ANOVA by main effects of training, $F(1,16)=31.7, p<.0001$, and testing $F(1,16)=12.8, p<.01$, and a significant interaction between the two, $F(1,16)=25.3, p<.0001$. Planned comparisons indicated that all of the APV-treated groups exhibited reliably lower freezing, compared with the CSFCSF controls, and that none of the APV-treated groups differed from one another. To rule out the possibility that
A

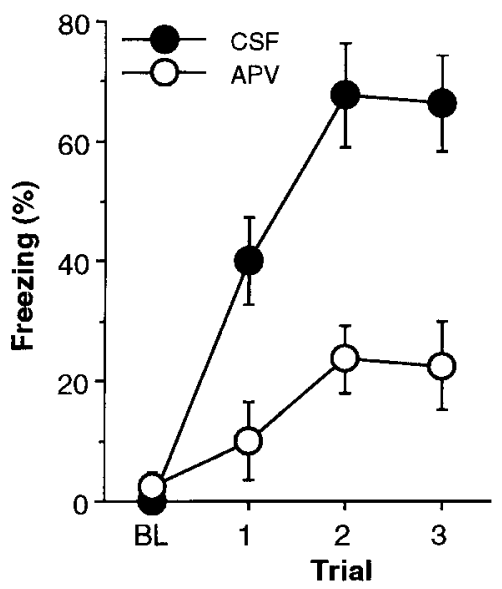

B

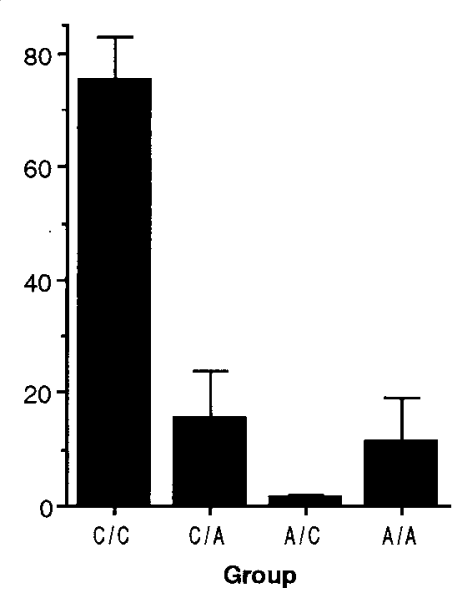

C

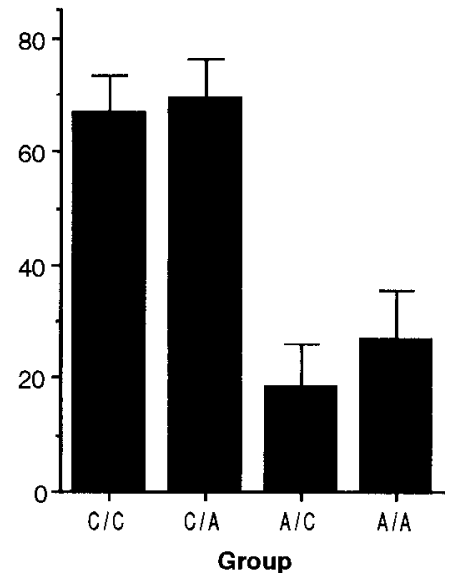

Figure 3. A: Mean percentage of freezing $( \pm S E M)$ during training in rats treated with either intra-amygdaloid D,L-2-amino-5-phosphonovalerate (APV) or artificial cerebrospinal fluid (CSF). Freezing was scored during the 64-s period before the first trial (BL) and during the 64-s periods after footshock, on each of the three trials. As before, intra-amygdaloid APV reliably attenuated the development of immediate postshock freezing. B: Mean percentage of freezing $( \pm S E M)$, averaged across the 8-min context-extinction test, in rats receiving APV or CSF infusion before training, testing, or both. $\mathrm{C} / \mathrm{C}=\mathrm{CSF}-\mathrm{CSF}, \mathrm{C} / \mathrm{A}=\mathrm{CSF}-\mathrm{APV}, \mathrm{A} / \mathrm{C}=\mathrm{APV}-\mathrm{CSF}, \mathrm{A} / \mathrm{A}=\mathrm{APV}-\mathrm{APV}$. All groups treated with APV (either before training, testing, or both) exhibited reliably lower levels of freezing than $\mathrm{C} / \mathrm{C}$ controls; none of the APV-treated groups differed from one another. C: Mean percentage of freezing $( \pm S E M)$, averaged across the second 8-min context-extinction test in the groups described in $B$. In this extinction test, no infusions were made before testing. Under these conditions, only the rats trained after intra-amygdaloid APV infusions (A/C, A/A) exhibited a reliable deficit in conditional freezing; rats in the C/A group showed a normal level of freezing when tested in the absence of APV. 
APV produced damage in the BLA that may have attenuated freezing, the rats were given an additional context-extinction test without intra-amygdaloid infusion of either CSF or APV. As shown in Figure $3 \mathrm{C}$, groups that received APV during training were still more impaired than were CSF-CSF controls. This suggests that APV impaired the acquisition of conditional fear, rather than producing a residual performance deficit. However, in contrast to the previous extinction test, CSF-APV rats (which were not under the influence of APV during the second extinction test) were not reliably different from CSF-CSF controls. This was confirmed by planned comparisons after a significant main effect of group, $F(3,16)=12.2, p<.0005$, in the ANOVA. These results indicate that the freezing deficits observed in the APVtreated rats were not due to damage in the BLA. More important, they indicate that the low levels of freezing in the CSF-APV rats during the first extinction test were due to an effect of APV on the performance of the conditional fear that was acquired normally during training.

Activity burst. As shown in Figure $4 \mathrm{~A}, \Delta$ grey was sensitive to both footshock occurrence and intensity. That is, $\Delta$ grey was significantly greater during the shock epoch, compared with the preshock epoch. This was indicated by a significant main effect of epoch in the ANOVA, $F(1,13)=$ $188.0, p<.0001$. Moreover, planned comparisons $(p<.05)$, following a reliable Group $\times$ Epoch interaction, $F(2,13)=$ $5.5, p<.02$, indicated that $\Delta$ grey was significantly greater during the shock in rats that received $1.0-\mathrm{mA}$ footshocks, compared with rats that received $0.5-\mathrm{mA}$ footshocks. This validates $\Delta$ grey as a measure of footshock-elicited activity bursts. With regard to intra-amygdaloid APV, planned comparisons indicated that rats receiving intra-amygdaloid APV infusion did not differ from CSF controls in the magnitude of their activity burst to the $1.0-\mathrm{mA}$ shocks used during training. They did, however, show significantly greater activity bursts than rats receiving $0.5-\mathrm{mA}$ footshocks. Freezing data during the delayed-context-extinction tests for each of the three groups is shown in Figure $4 \mathrm{~B}$ (the freezing data for the CSF and APV groups are the same as those shown in Figure 3A). Analysis of these data revealed significant differences between the groups, $F(2,13)=30.6$, $p<.0001$. Planned comparisons $(p<.05)$ indicated that rats that received intra-amygdaloid APV infusion exhibited lower levels of freezing than either the 1.0-mA-CSF controls or rats receiving $0.5-\mathrm{mA}$ shocks; rats receiving $0.5-\mathrm{mA}$ shocks froze less than 1.0-mA-CSF rats. Altogether, these data indicate that rats that received intra-amygdaloid APV showed a massive impairment in conditional freezing in the absence of a change in the footshock-elicited activity burst, and their freezing impairment was much greater than that produced by a manipulation (reduction in shock intensity) that substantially reduced the magnitude of the activity burst.

Collectively, the present results indicate that intraamygdaloid APV blocks both the acquisition and expression of contextual fear conditioning. The deficits in the acquisi-
A

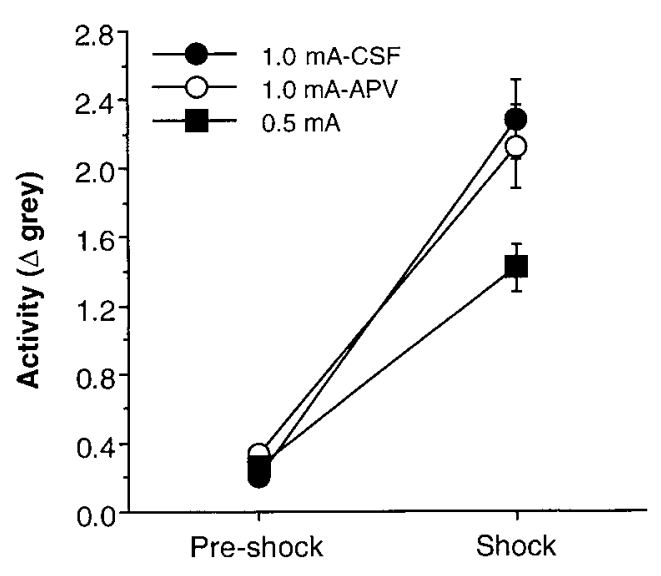

B

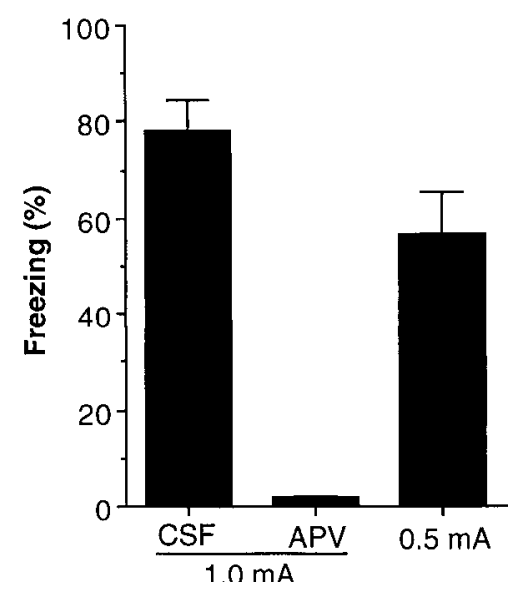

Figure 4. A: Mean activity ( $\triangle$ grey $\pm S E M$ ) for rats in the 1.0-mA-cerebrospinal fluid (CSF), 1.0 $\mathrm{mA}-\mathrm{D}, \mathrm{L}-2$-amino-5-phosphonovalerate (APV), and 0.5-mA groups, in 2-s epochs before (preshock) and during (shock) the first footshock of the training session. In relation to the preshock baseline, activity was significantly elevated in all groups during footshock. However, activity in both $1.0 \mathrm{~mA}$ groups was significantly greater than that in the $0.5-\mathrm{mA}$ group; intra-amygdaloid APV infusion did not affect the magnitude of the footshock-elicited activity burst. B: Mean percentage of freezing ( $\pm S E M$ ), averaged across the 8 -min context-extinction test in rats receiving 1.0-mA shocks (CSF and APV groups) or $0.5-\mathrm{mA}$ shocks. Conditional freezing was massively attenuated by intra-amygdaloid APV infusion, in relation to both the $1.0-\mathrm{mA}-\mathrm{CSF}$ group and the $0.5-\mathrm{mA}$ group. Freezing in the $0.5-\mathrm{mA}$ group was significantly lower than that in the $1.0-\mathrm{mA}$-CSF group. Thus, intra-amygdaloid APV infusion produced a massive impairment in fear conditioning in the absence of an effect on the activity burst. Moreover, the reduction in conditional freezing produced by APV treatment was even greater than that produced by a reduction in shock intensity, which was associated with a substantial decrease in the activity burst, depicted in $\mathrm{A}$. 
tion of fear conditioning were not the result of an APVinduced shift in US sensitivity, and the deficits in the expression of conditional freezing were not due to an APV-induced increase in motor activity, which may have interfered with the generation of freezing. The effects of APV on both the acquisition and expression of contextual fear are consistent with the effects of intra-amygdaloid APV on the acquisition and expression of an inhibitory avoidance response (Kim \& McGaugh, 1992) but are contrary to the selective effect of intra-amygdaloid APV on the acquisition of fear-potentiated startle (Campeau et al., 1992; Miserendino et al., 1990). The possible reasons for these discrepancies are discussed at length in the General Discussion section of this article. Nevertheless, the present results indicate that deficits in the acquisition of fear conditioning after intra-amygdaloid APV infusions (e.g., Fanselow \& Kim, 1994; Miserendino et al., 1990) were not due to state-dependent generalization decrements.

\section{Experiment 3}

The foregoing results suggest that pretraining APV attenuated conditional fear by disrupting an acquisition-related process. It remains possible, however, that the effect of APV was not to impair acquisition, but rather to impair a posttraining memory-consolidation process. To test this possibility, we made intra-amygdaloid APV infusions immediately after, rather than immediately before, fear conditioning. The subjects from Experiment 2 were used in this experiment, to permit an assessment of the effects of posttraining intra-amygdaloid APV infusion in rats for which effective cannula placements had already been established.

\section{Method}

Subjects. The subjects were those used in Experiment 2. One week after the last extinction test in Experiment 2, the rats were randomly assigned to two groups ( $n=10$ per group), which differed with respect to whether APV or CSF was infused into the BLA after training.

Behavioral apparatus and procedure. The behavioral apparatus was the same as that used in Experiment 1, which differed in many respects from the context in which the rats had previous experience. On the conditioning day, the rats were transported to the laboratory, placed in the conditioning chambers, and conditioned, as described in Experiment 2. Sixty-four seconds after the last footshock, the rats were removed from the observation chambers, transported to the infusion apparatus, and infused with either APV or CSF, according to the infusion procedures described in Experiment 1. After infusion, the rats were returned to their home cages and transported back to the vivarium. As described in Experiment 2, fear conditioning on the training day was assessed by measuring freezing during the 64-s period before the first (baseline) trial and after each of the three shock trials. We assessed fear conditioning to the training context by returning the rats to the conditioning chambers and scoring freezing during an 8-min extinction test, $24 \mathrm{hr}$ after training.

Histology. Histological verification of cannula location was performed according to the procedures described in Experiment 1 . Examination of the tissue sections revealed that all of the rats had bilaterally symmetric placements in the BLA (see Figure 1 for a representative placement).

Data analysis. Immediate postshock freezing data were submitted to a two-way ANOVA, with a between-subjects variable of group (2 levels: APV vs. CSF) and a within-subject variable of test period (4 levels: baseline vs. three postshock periods). Delayedfreezing data, collapsed across the 8-min test, were submitted to a one-way ANOVA, with a between-subjects variable of group ( 2 levels: APV vs. CSF). Planned comparisons in the form of Fisher's LSD tests were performed, following a significant omnibus $F$ ratio. All data are represented as means, plus or minus the standard errors of measurement.

\section{Results and Discussion}

Figure 5A shows immediate-postshock-freezing on the conditioning day. Rats in both groups showed negligible levels of preshock (baseline) freezing, which indicates that there was no generalization from their previous training. Moreover, both groups of rats acquired conditional freezing over the three training trials, and they did not differ in this regard. This was indicated in the ANOVA by a significant main effect of trial, $F(3,54)=34.0, p<.0001$, and a nonsignificant main effect of group, $F(1,18)=0.4, p=.54$, or Group $\times$ Trial interaction, $F(3,54)=0.8, p=.53$. Of course, this pattern of results was expected because the drug manipulation followed conditioning.

The effects of an immediate posttraining infusion of APV into the BLA on delayed freezing are shown in Figure 5B. In this graph, freezing is collapsed across the 8-min test. Posttraining APV did not impair conditional fear; rather, the tendency was for it to augment freezing on the delayed test. Thus, the main effect of group in the ANOVA was marginally nonsignificant, $F(1,18)=3.6, p=.07$. These results indicate that APV must be present in the BLA during, but not shortly after, training, to impair the acquisition of conditional fear. They also indicate that the freezing deficits in rats treated with APV during training during the delayedextinction tests (Experiment 3) were not due to a residual effect of APV on the performance of conditional fear.

\section{General Discussion}

The results of the present study indicate that infusion of the NMDA receptor antagonist APV into the BLA impairs the acquisition of Pavlovian fear conditioning to a contextual CS. This effect was evident in impairments of both immediate postshock freezing and conditional freezing expressed $24 \mathrm{hr}$ after training (Experiments 1 and 2). The similar activity bursts in CSF- and APV-treated rats suggests that APV was not blunting the impact of the footshock US. Thus, the impaired acquisition of conditional fear produced by APV was not due to a shift in US sensitivity. Moreover, the disruption of fear conditioning by intra-amygdaloid APV was not due to state-dependent generalization decrements in the performance of conditional fear (Experiment 2). Indeed, APV blocked conditional freezing when administered before training, testing, or both. Immediate posttraining infusions of APV into the BLA were ineffective in blocking conditional fear, suggesting that NMDA receptor activation 
A

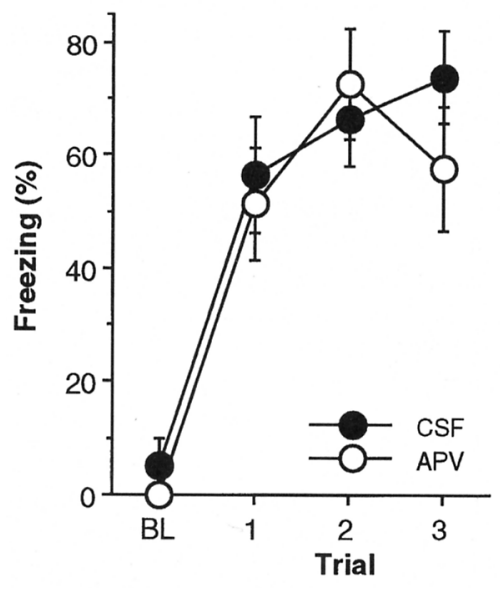

B

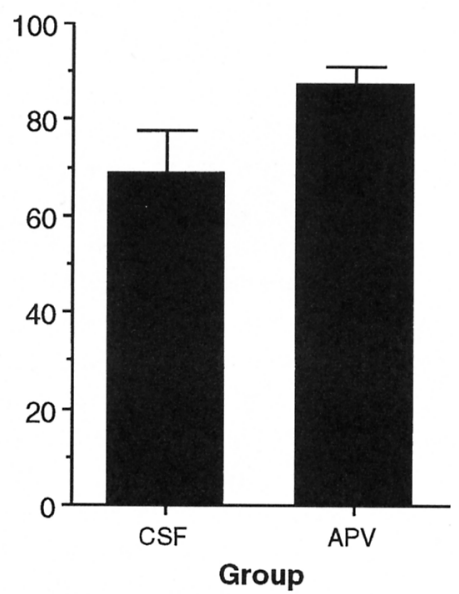

Figure 5. A: Mean percentage of freezing $( \pm S E M)$ during training, in rats that were to receive either intra-amygdaloid D,L-2-amino-5-phosphonovalerate (APV) or artificial cerebrospinal fluid (CSF), immediately after training (there was no pretraining infusion in these rats). Freezing was scored during the 64-s period before the first trial (BL) and during the 64-s periods after footshock on each of the three trials. Not surprisingly, freezing in the two groups of rats did not differ. B: Mean percentage of freezing ( $\pm S E M$ ), averaged across the 8-min context-extinction test, in rats receiving immediate posttraining infusions of either APV or CSF into the BLA. Immediate posttraining infusion of APV into the BLA did not attenuate the acquisition of conditional freezing.

during fear conditioning is critical for the acquisition of conditional freezing. Collectively, these results indicate that NMDA receptors in the BLA are required for both the acquisition and expression of short- and long-term conditional fear memories.

In general, the effects of intra-amygdaloid APV infusion on contextual fear conditioning are similar to those reported in the fear-potentiated startle paradigm, in which a discrete CS previously paired with footshock augments the acoustic startle response. Specifically, Miserendino et al. (1990) reported that APV infusion into the BLA blocks the acquisition of fear-potentiated startle, without affecting footshockinduced activity across a range of stimulus intensities. Thus, the acquisition of both conditional freezing to a contextual CS and potentiated startle to a discrete CS requires NMDA receptor activation in the BLA. However, in contrast to the present study, Campeau et al. (1992) and Miserendino et al. (1990) reported that intra-amygdaloid APV infusion does not affect the performance of fear-potentiated startle, whereas we found, in the present study, marked deficits in the performance of conditional fear after APV infusion into the BLA. The reasons for these discrepancies are not clear but may be related to the low level of fear-potentiated startle in subjects receiving CSF infusion before the test in Davis's experiments (e.g., Miserendino et al., 1990); this would obscure APV-induced decrements in the expression of conditional fear. Indeed, the infusion rate used in Miserendino et al.'s experiments is five times faster than that used in the present study, and we have found that this faster infusion rate produces deficits in the acquisition and expression of conditional freezing in CSF controls (Maren \& Fanselow, personal communication). Alternatively, the doses of APV used in the present study ( $5 \mu \mathrm{g} / \mathrm{side}$ ) and in another study that reported a deficit in the expression of inhibitory avoidance conditioning with intra-amygdaloid APV (10 $\mu \mathrm{g} / \mathrm{side}$; Kim \& McGaugh, 1992) were much higher than that used by Campeau et al. (1992) and Miserendino et al. (1990) (2.5 $\mu \mathrm{g} / \mathrm{side}$; Campeau et al., 1992; Miserendino et al., 1990). Doses of APV in the amygdala greater than $2.5 \mu \mathrm{g}$ may produce nonselective effects on the acquisition and expression of fear conditioning. Also, the expression of fear to contextual, but not discrete, CSs may require NMDA receptors.

In either case, the effect of intra-amygdaloid APV on the expression of conditional fear is not surprising, in the light of recent neurophysiological experiments. Using anesthetized rats, we characterized extracellular field potentials evoked in the BLA by stimulation of the ventral angular bundle (VAB), a fiber system that carries projections from the ventral subiculum, lateral entorhinal cortex, and caudal hippocampus to the BLA (Maren \& Fanselow, 1995). In these experiments, we found that intra-amygdaloid infusion of 6,7-dinitro-quinoxaline-2,3-dione (DNQX), a selective antagonist for the $\alpha$-amino-3-hydroxy-5-methyl-4-isoxazolepropionate (AMPA) subclass of glutamate receptors, massively attenuated VAB-evoked field potentials in the BLA, indicating that synaptic transmission in this putative contextual CS pathway is glutamatergic. Surprisingly, we also found that APV, although not attenuating the putatively synaptic component of VAB-evoked field potentials, produced a substantial attenuation of VAB-evoked spike firing in the BLA. These results indicate that both AMPA and NMDA receptors are required for spike firing in the BLA. Similar results have been reported for projections from the medial geniculate body to the lateral nucleus of the amygdala (Li, Phillips, \& LeDoux, 1995). Given the apparently 
critical role for NMDA receptors in normal synaptic transmission in the BLA, one would expect that the effects of APV in the BLA should parallel those of other manipulations that block synaptic transmission in the BLA, such as muscimol infusion. Indeed, infusion of muscimol into the BLA produces deficits in both the learning and performance of conditional fear (Helmstetter \& Bellgowan, 1994).

Not surprisingly, the effects of intra-amygdaloid APV infusion on the acquisition and expression of contextual fear are different from those reported with intracerebroventricular (ICV) infusions of APV (Kim, DeCola, LandeiraFernandez, \& Fanselow, 1991). First, ICV infusions of APV have been found to produce selective deficits on the acquisition of contextual fear conditioning expressed $24 \mathrm{hr}$ after training; that is, immediate postshock freezing is not affected by ICV APV. Second, ICV APV does not affect the expression of conditional freezing when infused before the context-extinction test. These divergent results are consistent with the idea that the primary site of action of ICV APV is the dorsal hippocampus, not the BLA. In keeping with this, ICV APV produces greater deficits in context, compared with tone fear conditioning (Fanselow, Kim, Yipp, \& De Oca, 1994), a result that parallels the effects of hippocampal (Maren \& Fanselow, 1995; Phillips and LeDoux, 1992), but not amygdaloid (Maren et al., 1996), lesions on the acquisition of fear. Alternatively, the different effects of ICV and intra-amygdaloid APV may have been due to the different tissue concentrations of APV obtained in the BLA after the two manipulations.

The present results indicate that NMDA receptors in the BLA are required for both the learning and performance of conditional fear memories. In keeping with these results, Kim and McGaugh (1992) showed that intra-amygdaloid APV infusion blocks both the acquisition and expression of inhibitory avoidance conditioning, another aversively motivated task (Kim \& McGaugh, 1992; but cf. Liang et al., 1994). Together, these results are not surprising in the light of the neurophysiological data described above and the critical role of neurons in the BLA in both the acquisition and expression of conditional fear (Maren et al., 1996; Sananes \& Davis, 1992) and inhibitory avoidance conditioning (Parent, West, \& McGaugh, 1994). However, in other conditioning tasks, BLA NMDA receptors have been found to have a unique role in the acquisition versus the expression of learned behavior. For example, intra-amygdaloid APV infusion selectively affects the acquisition of taste-potentiated odor aversion (Hatfield \& Gallagher, 1995) and discriminated approach to an appetitive CS (Burns, Everitt, \& Robbins, 1994). This pattern of results suggests that NMDA receptors may have a differential role in the acquisition and expression of learned responses in different behavioral tasks.

Although NMDA receptors play a role in both the acquisition and expression of contextual fear conditioning, they are not required immediately after training for the consolidation of contextual fear. That is, an immediate posttraining infusion of APV into the BLA did not attenuate the retention of contextual fear expressed $24 \mathrm{hr}$ after training. This result accords with the finding that ICV infusion of APV immediately after training fails to affect contextual fear conditioning (Kim et al., 1991). However, other studies reported that immediate posttraining infusion of APV into the BLA disrupts retention of inhibitory avoidance conditioning (Jerusalinsky et al., 1992; Liang et al., 1994). There are a number of differences between inhibitory avoidance conditioning and Pavlovian fear conditioning that might account for this difference, but in general, posttraining memory-consolidation processes have been more strongly implicated in the former, rather than the latter. As such, the lack of an effect of posttraining APV in the present study may be indicative of a minimal role of the BLA in the consolidation of classically conditioned fear.

Recognizing that intra-amygdaloid APV both blocks the learning and performance of contextual fear and attenuates hippocampo-amygdaloid synaptic transmission (Maren \& Fanselow, 1995), we must reconsider the hypothesis that the sole action of APV in the BLA is to prevent acquisitionrelated processes through a blockade of synaptic LTP (e.g., Fanselow \& Kim, 1994; Miserendino et al., 1990). Although the present results do not preclude a role for BLA NMDA receptor-dependent LTP in the acquisition of conditional fear, they indicate that NMDA receptors in the BLA have a more ubiquitous role in amygdaloid function than previously thought. Indeed, the effects of intra-amygdaloid APV on the acquisition and expression of fear conditioning may be mediated by a reduction in cell excitability ( $\mathrm{Li}$ et al., 1995; Maren \& Fanselow, 1995), rather than a blockade of synaptic plasticity. Additional experiments are required to further delineate the role of BLA NMDA receptors in the acquisition and expression of conditional fear.

\section{References}

Bliss, T. V. P., \& Collingridge, G. L. (1993). A synaptic model of memory: Long-term potentiation in the hippocampus. Nature (London), 361, 31-39.

Burns, L. H., Everitt, B. J., \& Robbins, T. W. (1994). Intraamygdala infusion of the $N$-methyl-D-aspartate receptor antagonist AP5 impairs acquisition but not performance of discriminated approach to an appetitive CS. Behavioral and Neural Biology, 61, 242-250.

Campeau, S., \& Davis, M. (1995). Involvement of the central nucleus and basolateral complex of the amygdala in fear conditioning measured with fear-potentiated startle in rats trained concurrently with auditory and visual conditioned stimuli. Journal of Neuroscience, 15, 2301-2311.

Campeau, S., Miserendino, M. J., \& Davis, M. (1992). Intraamygdala infusion of the $N$-methyl-D-aspartate receptor antagonist AP5 blocks acquisition but not expression of fearpotentiated startle to an auditory conditioned stimulus. Behavioral Neuroscience, 106, 569-574.

Chapman, P. F., Kairiss, E. W., Keenan, C. L., \& Brown, T. H. (1990). Long-term synaptic potentiation in the amygdala. Synapse, 6, 271-278.

Clugnet, M. C., \& LeDoux, J. E. (1990). Synaptic plasticity in fear conditioning circuits: Induction of LTP in the lateral nucleus of the amygdala by stimulation of the medial geniculate body. Journal of Neuroscience, 10, 2818-2824.

Collingridge, G. L., Kehl, S. J., \& McLennan, H. (1983). Excitatory amino acids in synaptic transmission in the Schaffer collateral-commissural pathway of the rat hippocampus. Journal of Physiology, 334, 33-46. 
Davis, M. (1992). The role of the amygdala in fear and anxiety. Annual Review of Neuroscience, 15, 353-375.

Davis, M., Rainnie, D., \& Cassell, M. (1994). Neurotransmission in the rat amygdala related to fear and anxiety. Trends in Neurosciences, 17, 208-214.

Fanselow, M. S. (1993). Associations and memories: The role of NMDA receptors and long-term potentiation. Current Directions in Psychological Science, 2, 152-156.

Fanselow, M. S., DeCola, J. P., \& Young, S. L. (1993). Mechanisms responsible for reduced contextual conditioning with massed unsignaled unconditional stimuli. Journal of Experimental Psychology: Animal Behavior Processes, 19, 121-137.

Fanselow, M. S., \& Kim, J. J. (1994). Acquisition of contextual Pavlovian fear conditioning is blocked by application of an NMDA receptor antagonist $\mathrm{D}, \mathrm{L}-2$-amino-5-phosphonovaleric acid to the basolateral amygdala. Behavioral Neuroscience, 108, 210-212.

Fanselow, M. S., Kim, J. J., Yipp, J., \& De Oca, B. (1994). Differential effects of the $N$-methyl-D-aspartate antagonist D,L-2amino-5-phosphonovalerate on acquisition of fear of auditory and contextual cues. Behavioral Neuroscience, 108, 235-240.

Fanselow, M. S., \& Tighe, T. J. (1988). Contextual conditioning with massed versus distributed unconditional stimuli in the absence of explicit conditional stimuli. Journal of Experimental Psychology: Animal Behavior Processes, 14, 187-199.

Hatfield, T., \& Gallagher, M. (1995). Taste-potentiated odor conditioning impairment produced by infusion of an $N$-methyl-Daspartate antagonist into basolateral amygdala. Behavioral $\mathrm{Neu}$ roscience, 109, 663-668.

Helmstetter, F. J. (1992). The amygdala is essential for the expression of conditional hypoalgesia. Behavioral Neuroscience, 106, 518-528.

Helmstetter, F. J., \& Bellgowan, P. S. (1994). Effects of muscimol applied to the basolateral amygdala on acquisition and expression of contextual fear conditioning in rats. Behavioral Neuroscience, 108, 1005-1009.

Jerusalinsky, D., Ferreira, M. B. C., Walz, R., da Silva, R. C., Bianchin, M., Ruschel, A. C., Zanatta, M. S., Medina, J. H., \& Izquierdo, I. (1992). Amnesia by post-training infusion of glutamate receptor antagonists into the amygdala, hippocampus, and entorhinal cortex. Behavioral and Neural Biology, 58, 76-80.

Kelso, S., Ganong, A. H., \& Brown, T. H. (1986). Hebbian synapses in hippocampus. Proceedings of the National Academy of Sciences, USA, 83, 5326-5330.

Kim, J. J., DeCola, J. P., Landeira-Fernandez, J., \& Fanselow, M. S. (1991). $N$-methyl-D-aspartate receptor antagonist APV blocks acquisition but not expression of fear conditioning. Behavioral Neuroscience, 105, 126-133.

Kim, M., \& McGaugh, J. L. (1992). Effects of intra-amygdala injections of NMDA receptor antagonists on acquisition and retention of inhibitory avoidance. Brain Research, 585, 35-48.

LeDoux, J. E. (1995). Emotion: Clues from the brain. Annual Review of Psychology, 46, 209-235.
Li, X. F., Phillips, R., \& LeDoux, J. E. (1995). NMDA and non-NMDA receptors contribute to synaptic transmission between the medial geniculate-body and the lateral nucleus of the amygdala. Experimental Brain Research, 105, 87-100.

Liang, K. C., Hon, W., \& Davis, M. (1994). Pre- and posttraining infusion of $N$-methyl-D-aspartate receptor antagonists into the amygdala impair memory in an inhibitory avoidance task. Behavioral Neuroscience, 108, 241-253.

Maren, S., Aharonov, G., \& Fanselow, M. S. (1996). Retrograde abolition of conditional fear after excitotoxic lesions in the basolateral amygdala of rats: Absence of a temporal gradient. Behavioral Neuroscience, 110, 718-726.

Maren, S., Baudry, M., \& Thompson, R. F. (1992). Effects of the novel NMDA receptor antagonist, CGP 39551, on field potentials and the induction and expression of LTP in the dentate gyrus in vivo. Synapse, $11,221-228$.

Maren, S., \& Fanselow, M. S. (1995). Synaptic plasticity in the basolateral amygdala induced by hippocampal formation stimulation in vivo. Journal of Neuroscience, 15, 7548-7564.

Maren, S., \& Fanselow, M. S. (1996). The amygdala and fear conditioning: Has the nut been cracked? Neuron, 16, 237-240.

Maren, S., Poremba, A., \& Gabriel, M. (1991). Basolateral amygdaloid multi-unit neuronal correlates of discriminative avoidance learning in rabbits. Brain Research, 549, 311-316.

Miserendino, M. J., Sananes, C. B., Melia, K. R., \& Davis, M. (1990). Blocking of acquisition but not expression of conditioned fear-potentiated startle by NMDA antagonists in the amygdala. Nature (London), 345, 716-718.

Parent, M. B., West, M., \& McGaugh, J. L. (1994). Memory of rats with amygdala lesions induced 30 days after footshockmotivated escape training reflects degree of original training. Behavioral Neuroscience, 108, 1080-1087.

Phillips, R. G., \& LeDoux, J. E. (1992). Differential contribution of amygdala and hippocampus to cued and contextual fear conditioning. Behavioral Neuroscience, 106, 274-285.

Quirk, G. J., Repa, J. C., \& LeDoux, J. E. (1995). Fear conditioning enhances short-latency auditory responses of lateral amygdala neurons: Parallel recordings in the freely behaving rat. Neuron, 15, 1029-1039.

Sah, P., Hestrin, S., Nicoll, R. A. (1989). Tonic activation of NMDA receptors by ambient glutamate enhances excitability of neurons. Science, 246, 815-818.

Sananes, C. B., \& Davis, M. (1992). N-methyl-D-aspartate lesions of the lateral and basolateral nuclei of the amygdala block fear-potentiated startle and shock sensitization of startle. Behavioral Neuroscience, 106, 72-80.
Received December 14, 1995

Revision received March 8, 1996 Accepted May 2, 1996 